\title{
Host-controlled Modification and Restriction of Phages in Coagulase-negative Staphylococci
}

\author{
By J. VERHOEF, ${ }^{*}$ C. P. A. VAN BOVEN AND BERNARDA \\ HOLTRIGTER \\ Laboratory of Microbiology, University of Utrecht, \\ Utrecht, The Netherlands
}

(Accepted for publication 25 January 1972)

\section{SUMMAR Y}

Three host-controlled modification and restriction systems occurring among coagulase-negative staphylococci belonging to the Staphylococcus subgroup II are described. The phage patterns, observed by typing the staphylococci with a provisional typing set of eighteen phages, are mainly determined by these host specificity systems. A strain, which was not restrictive to the phages, did not become restrictive after lysogenization with any of the eighteen phages.

Infection of a restricting host with ${ }^{3} \mathrm{H}$-labelled phages was followed by a rapid breakdown of phage DNA, as demonstrated by the appearance of radioactive label in the cold-acid-soluble DNA fraction of extracted adsorption mixtures.

\section{INTRODUCTION}

Recently a provisional phage typing system for Staphylococcus subgroup II (Staphylococcus epidermidis biotype I) strains (Baird-Parker, 1963; 1965) has been described (van Boven, Verhoef, \& Winkler, I969; Verhoef, van Boven \& Winkler, 1971 $b$, I972).

A limited number of distinct phage patterns, referred to as 'main patterns', occurred frequently (Verhoef et al. 1972). The phage patterns of the majority of the typable strains were similar or related to one of these main patterns.

With the typing phages at routine test dilution (RTD), the main patterns did not overlap. At RTD $\times 1000$ the patterns broadened considerably by the occurrence of additional weak phage reactions.

These strain differences in susceptibility are not due to differences in adsorption to subgroup II strains (Verhoef et al. I97I $b$ ). Since only a low proportion of lysogenic strains has been found among staphylococcal subgroup II strains (Verhoef, van Boven \& Winkler, I97I $a$ ), immunity seems also to be an unlikely explanation for the differences in sensitivity.

We show that the differences in susceptibility to the phages can, for the most part be explained by host-controlled modification. Evidence is presented for the occurrence of three modification and restriction systems. A preliminary report of this study has been presented (Verhoef, van Boven \& Holtrigter, I971).

* Present address: Laboratory of Medical Microbiology of the Free University, De Boelelaan I1 I7, Amsterdam-Buitenveldert, The Netherlands. 


\section{METHODS}

Strains. The Staphylococcus subgroup II (Staphylococcus epidermidis biotype I) strains used were the set of propagating strains and additional indicator strains previously used to characterize the host range of the phages (Verhoef et al. 197 I b). The isolation and identification of these strains have been described (Verhoef et al. 197 I a). Strain 407, used as general indicator strain, is sensitive to all phages. Although tested repeatedly, it could not be shown to carry a phage and is probably non-lysogenic.

Media. Nutrient Broth or Nutrient Agar (Difco) and peptone water (Bacto peptone, Difco, $\mathrm{I} \%$, w/v and $\mathrm{NaCl} 0.5 \%$ w/v). To all media $0.004 \mathrm{M}-\mathrm{CaCl}_{2}$ was added.

Phages. The eighteen typing phages described by Verhoef et al. (197I $b$ ) were used. When necessary, the number of the propagating strain is given following the phage number.

To indicate modification type carried by a phage, host specificity type or phenotype of a host, the conventional notation was followed (Arber \& Linn, 1969).

Phage assay. Standardized drops $(0.03 \mathrm{ml})$ of serial Io-fold dilutions of phage lysates in broth were spotted in duplicate on to strains spread on the surface of agar plates. Plaques were counted after incubation for $24 \mathrm{~h}$ at $37^{\circ} \mathrm{C}$. The efficiency of plating (e.o.p.) was determined by simultaneous titration of a phage lysate on its propagating strain and a given test strain, and is expressed as the ratio of the titres.

Host range determination of phage lysates on a number of strains was done as described by Blair \& Williams (196I).

Lysogenization. High titre phage lysates were spotted on to plates seeded with a $24 \mathrm{~h}$ broth culture. After incubation for $24 \mathrm{~h}$ at $37^{\circ} \mathrm{C}$, secondary growth in the areas of confluent lysis was isolated and purified by repeated single colony isolation.

Lysogeny was confirmed by testing for immunity to the corresponding phage and by demonstrating phage action when cultures were streaked across the general indicator strain 407 .

Labelling of phage DNA with $\left[{ }^{3} \mathrm{H}\right]$ thymidine. Phage lysates were prepared in peptone water containing per $\mathrm{ml}$ ro $\mu \mathrm{Ci}\left[{ }^{3} \mathrm{H}\right]$ thymidine with a specific activity of $83.5 \mathrm{mCi} / \mathrm{mg}$. The labelled phages were purified by one cycle of differential centrifugation, and then resuspended

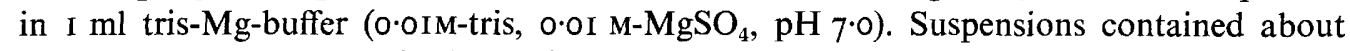
$5 \times 10^{9}$ plaque-forming units (p.f.u.) $/ \mathrm{ml}$.

Assay of phage DNA degradation. One ml bacterial suspension containing $10^{9}$ to $10^{10}$ cells grown overnight were thoroughly mixed with $\mathrm{I} \mathrm{ml}$ phage lysate ( $10^{9}$ to $10^{10}$ p.f.u.). After adsorption for 30 min at $0{ }^{\circ} \mathrm{C}$, the cells were washed twice and resuspended in $\mathrm{I} \cdot 5 \mathrm{ml}$ warmed broth. Immediately, i.e. within one min after resuspending the cells (zero-time sample) and at various intervals during incubation at $37^{\circ} \mathrm{C}, 0.2 \mathrm{ml}$ samples were taken and added to nine vol. of cold trichloroacetic acid. After standing for $30 \mathrm{~min}$ at $0^{\circ} \mathrm{C}$, this mixture was filtered (Oxoid membrane filter, grade 0.545 ; Oxoid Ltd), and the filtrate was added to $20 \mathrm{ml}$ scintillation fluid (triton X-I00:toluene $=3: 7, \mathrm{v} / \mathrm{v}$ ) and counted (Corumatic- 100 , Tracerlab). Radioactivity is expressed as the number of disintegrations per min (d.p.m.).

\section{RESULTS}

Main lytic patterns. The lytic reactions of the I 8 typing phages on their propagating strains and on two additional indicator strains are shown in Table I, and are arranged into seven main patterns which could also be found in naturally isolated strains (Verhoef et al. 1972). The patterns fall into three groups which appeared at RTD to be mutually exclusive. 
Table I. Main phage patterns of Staphylococcus subgroup II strains with the set of phages at RTD

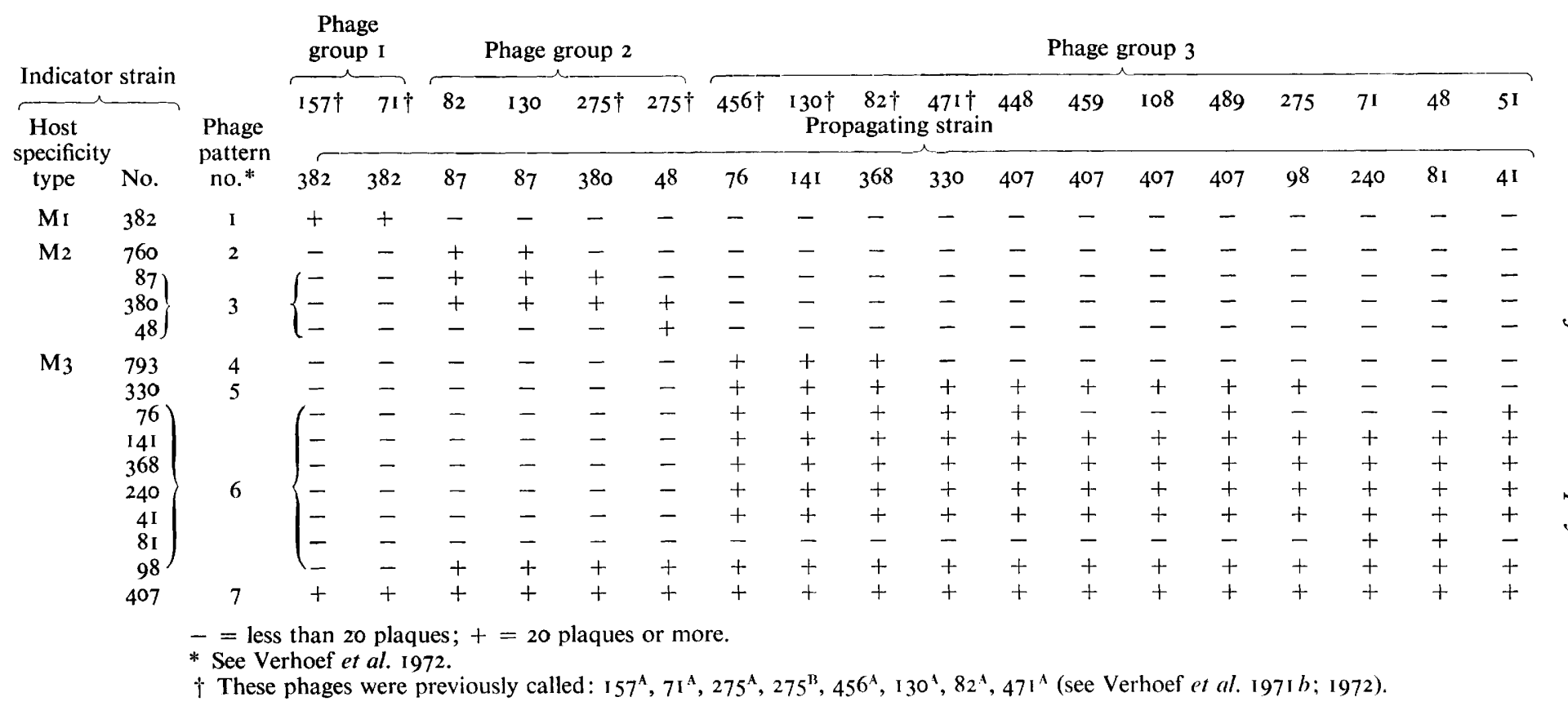


The strains could therefore be classified into one of three groups leaving a fourth group, represented by strain 407 , susceptible to all phages. Consequently the phages could also be allotted to one of three groups, each group comprising phages with similar host range. It then became apparent that strains within a group were lysed only by phages propagated on strains belonging to that group.

These interrelations might be explained by assuming that the phages undergo hostcontrolled modification and restriction. The arrangement of the strains into groups would then imply that different host specificity types are involved, the first three groups representing strains able to modify and to restrict phages, i.e. phenotypically $\mathrm{r}^{+} \mathrm{m}^{+}$, but of different host

Table 2. Efficiency of plating of phage variants carrying different modifications on different host strains

\begin{tabular}{|c|c|c|c|c|c|}
\hline \multicolumn{3}{|c|}{ Phage variant } & \multicolumn{3}{|c|}{ Host } \\
\hline No. & $\begin{array}{l}\text { Passed through } \\
\text { strains }\end{array}$ & $\begin{array}{l}\text { Modifi- } \\
\text { cation }\end{array}$ & 240 & 382 & 407 \\
\hline \multirow[t]{5}{*}{71} & 240 & M3 & $I \cdot O$ & $2.5 \times 10^{-5}$ & $1 \cdot 0$ \\
\hline & $240.3^{82}$ & MI & $1 \cdot 6 \times 10^{-3}$ & I $\cdot 0$ & $1 \cdot 0$ \\
\hline & 240.382 .240 & $\mathrm{M}_{3}$ & $1 \cdot 0$ & $3.3 \times 10^{-5}$ & $I^{\circ} \mathrm{O}$ \\
\hline & 240.382 .240 .382 & Mi & $8.2 \times 10^{-2}$ & $1 \cdot 0$ & $I \cdot O$ \\
\hline & & & 87 & 368 & 407 \\
\hline \multirow[t]{5}{*}{82} & 87 & $\mathrm{M} 2$ & $I \cdot O$ & $1 \cdot 2 \times 10^{-3}$ & $1 \cdot 0$ \\
\hline & 87.368 & $\mathrm{M}_{3}$ & $1 \cdot 2 \times 10^{-4}$ & $I \cdot 0$ & $1 \cdot 0$ \\
\hline & 87.368 .87 & $\mathrm{M} 2$ & I 0 & $2.0 \times 10^{-3}$ & I'O \\
\hline & $87 \cdot 368.87 \cdot 368$ & $\mathrm{M}_{3}$ & $1.0 \times 10^{-3}$ & $1 \cdot 0$ & $I \cdot O$ \\
\hline & & & 87 & I4 I & 407 \\
\hline \multirow[t]{5}{*}{130} & 87 & M2 & $I \cdot O$ & $5.0 \times 10^{-3}$ & $I \cdot 0$ \\
\hline & 87.141 & $\mathrm{M}_{3}$ & $1.4 \times 10^{-3}$ & $1 \cdot 0$ & $1 \cdot 0$ \\
\hline & 87.141 .87 & M2 & $\mathrm{I} \cdot \mathrm{O}$ & $2.5 \times 10^{-3}$ & $I \cdot O$ \\
\hline & $87.14 \mathrm{I} .87 . \mathrm{I} 4 \mathrm{I}$ & $\mathrm{M}_{3}$ & $3.0 \times 10^{-3}$ & $1 \cdot 0$ & $\mathrm{I} \cdot \mathrm{O}$ \\
\hline & & & 98 & 48 & 407 \\
\hline \multirow[t]{4}{*}{275} & 98 & M3 & $I \cdot O$ & $0.5 \times 10^{-4}$ & $I \cdot O$ \\
\hline & 98.48 & $\mathrm{M} 2$ & $1.5 \times 10^{-2}$ & 1.0 & $I \cdot O$ \\
\hline & 98.48 .98 & M3 & $\mathrm{I} \cdot \mathrm{O}$ & $0.6 \times 10^{-5}$ & I $\cdot 0$ \\
\hline & 98.48 .98 .48 & $\mathrm{M} 2$ & $1.0 \times 10^{-1}$ & $\mathrm{I} \cdot \mathrm{O}$ & $1 \cdot 0$ \\
\hline
\end{tabular}

specificity type. Strain 407 imparts a host specificity type identical to that of the strains of the third group as indicated by the host range of the phages 448,459 , 108 and 489 propagated on this strain. However, it clearly does not restrict the phages and can therefore be represented phenotypically as $\mathrm{r}^{-} \mathrm{m}^{+}$. In Table $\mathrm{I}$ these host specificity types are designated $\mathrm{M}_{1}, \mathrm{M}_{2}$, and M3.

Definition of modification and restriction systems. Several phage-host systems of supposedly different host specificity type were selected and analysed. Lysates were prepared alternatively on two host strains and subsequently titrated on both strains and on the supposedly non-restrictive strain 407. The efficiencies of plating, compared with e.o.p. on the last host strain which was arbitrarily put equal to $I \cdot 0$, are given in Table 2 . For phage 7 I propagated on strain 240 , the plating efficiency on strain 382 was $2.5 \times 10^{-5}$; however, when the phage was propagated on 382 (second line), the e.o.p. on the strain was low. In all cases the ratio of plating efficiencies was reversed by growing the phages on the other host, and this could be repeated by alternating the host strains. 


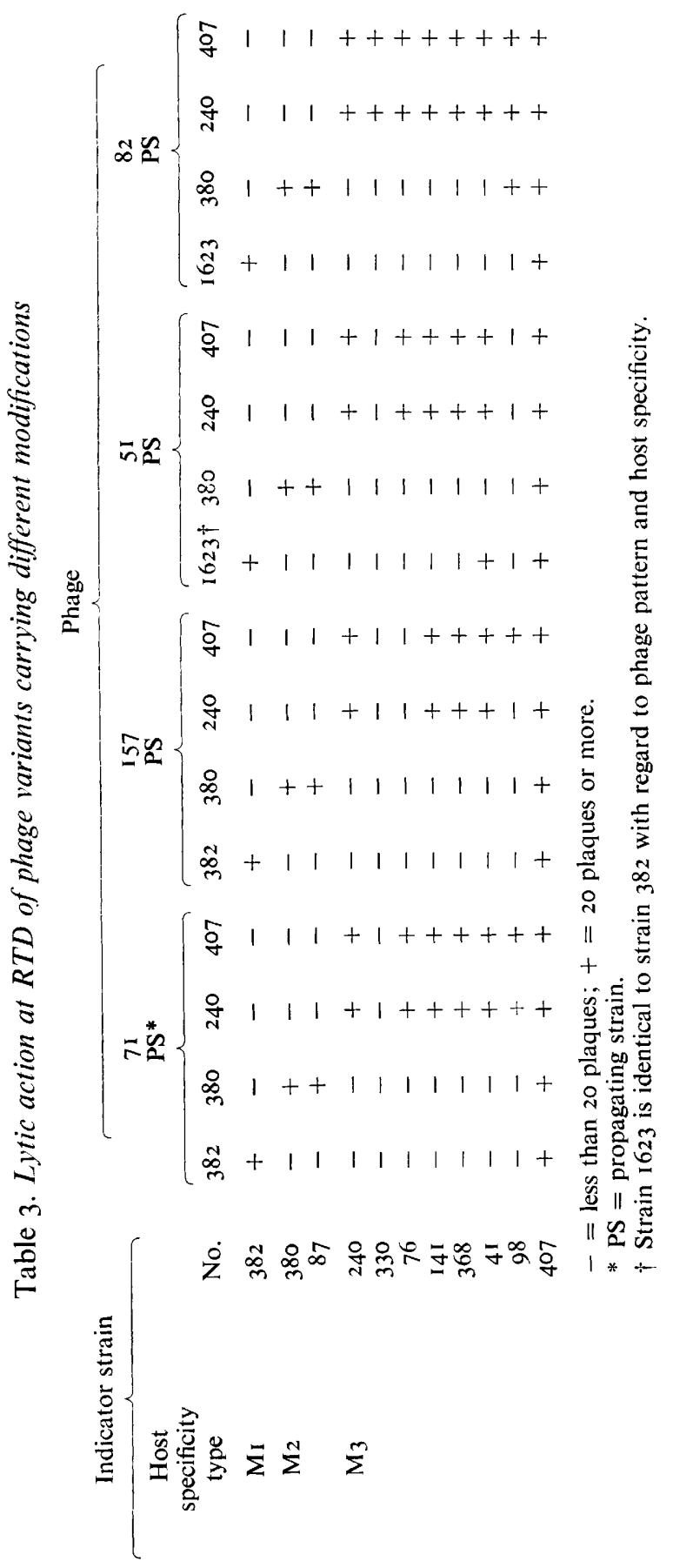


In each case the phage acquires the host specificity of its last host. It can further be seen from Table 2 that irrespective of the host in which the phage was grown, it retained its ability to plate on strain 407 with an e.o.p. equal to $\mathrm{I} \cdot 0$. The results exclude the possibility of host range mutation or contaminating phages as an explanation, and support the assumption that these staphylococcal strains possess characteristic host specificity systems. Although only a limited number of the possible phage-host combinations has been examined, it seems justifiable to infer from the results that among these staphylococci at least three different host-controlled modification and restriction systems occur.

Table 4. Lytic action at RTD of phage variants carrying different modifications on lysogenic derivatives of strain 407

\begin{tabular}{|c|c|c|c|c|c|c|c|c|c|c|c|c|}
\hline \multirow{3}{*}{$\begin{array}{c}\text { Phage } \\
\text { carried by } \\
\text { strain } 407\end{array}$} & \multicolumn{12}{|c|}{ Phage } \\
\hline & \multicolumn{3}{|c|}{$\begin{array}{c}7 \mathrm{I} \\
\mathrm{MT}^{*}\end{array}$} & \multicolumn{3}{|c|}{$\begin{array}{l}\text { I } 57 \\
\text { MT }\end{array}$} & \multicolumn{2}{|c|}{$\begin{array}{c}82 \\
\mathrm{MT}\end{array}$} & \multicolumn{2}{|c|}{$\begin{array}{l}130 \\
\text { MT }\end{array}$} & \multicolumn{2}{|c|}{$\begin{array}{l}275 \\
\text { MT }\end{array}$} \\
\hline & MI & $\mathrm{M} 2$ & $\mathrm{M}_{3}$ & MI & $\mathrm{M} 2$ & $\mathrm{M}_{3}$ & $\mathrm{M} 2$ & $\mathrm{M}_{3}$ & M2 & $\mathrm{M}_{3}$ & $\mathrm{M} 2$ & $M_{3}$ \\
\hline $157 \dagger$ & - & - & - & - & - & - & + & + & + & + & + & + \\
\hline $71 \dagger$ & - & - & - & - & - & - & + & + & + & + & + & + \\
\hline 71 & - & - & - & - & - & - & + & + & + & + & + & + \\
\hline 48 & - & - & - & - & - & - & + & + & + & + & + & + \\
\hline $5 \mathrm{I}$ & - & - & - & - & - & - & + & + & + & + & + & + \\
\hline $275^{\dagger}$ & - & - & - & - & - & - & + & + & + & + & + & + \\
\hline $471 \dagger$ & - & - & - & - & - & - & + & - & + & + & - & - \\
\hline $44^{8}$ & - & - & - & - & - & - & + & - & + & + & - & - \\
\hline 82 & - & - & - & - & - & - & V & - & V & V & - & - \\
\hline $82 \dagger$ & - & - & - & - & - & - & V & - & V & V & - & - \\
\hline 130 & - & - & - & - & - & - & + & + & V & V & - & - \\
\hline I30† & - & - & - & - & - & - & + & + & V & V & - & - \\
\hline $456 \dagger$ & - & - & - & - & - & - & + & + & V & V & - & - \\
\hline 275 & + & + & + & + & + & + & V & V & V & + & - & - \\
\hline $275 \dagger$ & + & + & + & + & + & + & V & V & V & + & - & - \\
\hline 489 & V & V & V & V & V & V & - & - & - & - & V & - \\
\hline 459 & V & V & V & V & V & V & - & - & - & - & V & - \\
\hline 108 & V & V & V & V & V & V & - & - & - & - & - & - \\
\hline
\end{tabular}

$-=$ less than 20 plaques; $+=20$ plaques or more; Phage titre $I \times$ RTD.

$\mathrm{V}=$ variable results, which means that in different experiments occasional contradictory reactions have been obtained.

$* \mathrm{MT}=$ modification type; for host strains see Table 3.

$\dagger$ See legend Table $\mathrm{I}$.

The host-range of four phages, each grown on different hosts, representing the three specificity types and on strain 407 , are given in Table 3 . In each case the lytic patterns obtained with the four variants of each phage depend mainly on the propagating strain used. The patterns closely resemble the groups of lytic patterns given in Table I.

This implies that the lytic patterns of the staphylococci are determined predominantly by the three modification and restriction systems occurring among these staphylococci. The patterns of the phages propagated on strain 407 are identical with those after propagation on strain 240 ; this indicates that strain 407 , which is not restrictive, imparts to phages a modification type identical to that of the $\mathrm{M}_{3}$ system.

The non-restricting and probably also non-lysogenic strain 407 provided the additional possibility of investigating whether the presence of a prophage of one of the temperate typing phages played a role in controlling restriction. Lysogenic derivatives of strain 407 were prepared with each of the typing phages and examined for their susceptibility to phage 
lysates of different modification type. The results, exemplified by the lytic patterns obtained with five phages and their variants, are given in Table 4.

Variable sensitivities of some of the lysogenic cultures were noted on repeated testing, or when several colonies were examined. Nevertheless, the host-range of the phage lysates is independent of the strain on which the phage was propagated and seems to be related only to the prophage carried by strain 407 . Strain 407 did not become restrictive after lysogenization by any of these phages. No definite explanation can at yet be given for the differences in lytic action between phage $82 . \mathrm{M}_{3}$ and phage $82 . \mathrm{M} 2$ on strains $407\left(47 \mathrm{I}_{\mathrm{Q}}^{\mathrm{A}}\right)$ and 407 (448).

\title{
Table 5. Breakdown of ${ }^{3} \mathrm{H}$-labelled phage DNA after infection of restrictive host strains
}

\begin{abstract}
Phages, from which DNA was labelled with $\left[{ }^{3} \mathrm{H}\right]$ thymidine, were incubated with the strains 407 , I4I, 380 and 382 . At different times samples were taken, and shaken with cold TCA and the acidsoluble radioactivity was counted.
\end{abstract}

\begin{tabular}{|c|c|c|c|c|c|}
\hline \multicolumn{3}{|c|}{ Adsorption mixture } & \multirow{2}{*}{\multicolumn{3}{|c|}{$\begin{array}{l}\text { DPM }\left(\times 10^{-2}\right) \\
\text { assayed after incubation } \\
\text { for }\end{array}$}} \\
\hline \multirow{2}{*}{$\begin{array}{l}\text { Phage } \\
\text { variant }\end{array}$} & \multicolumn{2}{|r|}{ Host } & & & \\
\hline & No. & Phenotype* & 0 min & Io to $15 \mathrm{~min}$ & $30 \mathrm{~min}$ \\
\hline $82 \cdot \mathrm{M}_{3}$ & $\begin{array}{l}407 \\
141 \\
380 \\
382\end{array}$ & $\begin{array}{l}\mathrm{r}_{\mathrm{m} 3}^{-} \mathrm{m}_{\mathrm{m} 3}^{+} \\
\mathrm{r}_{\mathrm{m} 3}^{+} \mathrm{m}_{\mathrm{m} 3}^{+} \\
\mathrm{r}_{\mathrm{m} 2}^{+} \mathrm{m}_{\mathrm{m} 2}^{+} \\
\mathrm{r}_{\mathrm{m} 1}^{+} \mathrm{m}_{\mathrm{m} 1}^{+}\end{array}$ & $\begin{array}{l}2 \cdot 3 \\
3 \cdot 0 \\
3 \cdot 0 \\
5 \cdot 1\end{array}$ & $\begin{array}{r}2 \cdot 1 \\
4.0 \\
135.0 \\
388 \cdot 5\end{array}$ & $\begin{array}{r}3 \cdot 1 \\
5 \cdot 0 \\
300 \cdot 0 \\
530 \cdot 0\end{array}$ \\
\hline $82 . \mathrm{M} 2$ & $\begin{array}{l}407 \\
380 \\
141 \\
382\end{array}$ & $\begin{array}{l}\mathrm{r}_{\mathrm{m} 3}^{-} \mathrm{m}_{\mathrm{m} 3}^{+} \\
\mathrm{r}_{\mathrm{m} 2}^{+} \mathrm{m}_{\mathrm{m} 2}^{+} \\
\mathrm{r}_{\mathrm{m} 3}^{+} \mathrm{m}_{\mathrm{m} 3}^{+} \\
\mathrm{r}_{\mathrm{m} 1}^{+} \mathrm{m}_{\mathrm{m} 1}^{+}\end{array}$ & $\begin{array}{l}2 \cdot 7 \\
3 \cdot 5 \\
2 \cdot 8 \\
4 \cdot 0\end{array}$ & $\begin{array}{l}12 \cdot 0 \\
10 \cdot 0 \\
48 \cdot 0 \\
70 \cdot 0\end{array}$ & $\begin{array}{l}15 \cdot 0 \\
10 \cdot 5 \\
36 \cdot 0 \\
70 \cdot 0\end{array}$ \\
\hline $\mathrm{I}_{57} \cdot \mathrm{M}_{3}$ & $\begin{array}{l}407 \\
141 \\
380 \\
382\end{array}$ & $\begin{array}{l}\mathrm{r}_{\mathrm{m} 3}^{-} \mathrm{m}_{\mathrm{m} 3}^{+} \\
\mathrm{r}_{\mathrm{m} 3}^{+} \mathrm{m}_{\mathrm{m} 3}^{+} \\
\mathrm{r}_{\mathrm{m} 2}^{+} \mathrm{m}_{\mathrm{m} 2}^{+} \\
\mathrm{r}_{\mathrm{m} 1}^{+} \mathrm{m}_{\mathrm{m} 1}^{+}\end{array}$ & $\begin{array}{r}10.7 \\
5.8 \\
7.4 \\
5.8\end{array}$ & $\begin{array}{r}8 \cdot 3 \\
8 \cdot 9 \\
38 \cdot 7 \\
23 \cdot 7\end{array}$ & $\begin{array}{r}6 \cdot I \\
6 \cdot 6 \\
43 \cdot 3 \\
26 \cdot 0\end{array}$ \\
\hline I $57 . \mathrm{M} 2$ & $\begin{array}{l}407 \\
380 \\
141 \\
382\end{array}$ & $\begin{array}{l}\mathrm{r}_{\mathrm{m} 3}^{-} \mathrm{m}_{\mathrm{m} 3}^{+} \\
\mathrm{r}_{\mathrm{m} 2}^{+} \mathrm{m}_{\mathrm{m} 2}^{+} \\
\mathrm{r}_{\mathrm{m} 3}^{+} \mathrm{m}_{\mathrm{m} 3}^{+} \\
\mathrm{r}_{\mathrm{m} 1}^{+} \mathrm{m}_{\mathrm{m} 1}^{+}\end{array}$ & $\begin{array}{r}12 \cdot 3 \\
8 \cdot 5 \\
16 \cdot 5 \\
21 \cdot 7\end{array}$ & $\begin{array}{r}10 \cdot 7 \\
9 \cdot 8 \\
25 \cdot 6 \\
65 \cdot 3\end{array}$ & $\begin{array}{l}10 \cdot 5 \\
12 \cdot 9 \\
21 \cdot 3 \\
68 \cdot 2\end{array}$ \\
\hline
\end{tabular}

* Phenotype: $\mathrm{r}_{\mathrm{m} 3}^{+} \mathrm{m}_{\mathrm{m} 3}^{+}$: restricting and modifying strain of host specificity type $\mathrm{M}_{3}$.

Degradation of restricted phage DNA. To assay the breakdown of phage DNA upon infection of a restricting host, labelled lysates of the phages 82 and 157 were used in a series of experiments with four host strains, i.e. the $\mathrm{r}^{-}$strain 407 and the $\mathrm{r}^{+}$strains 382,380 and I4I of $\mathrm{M}_{1}, \mathrm{M}_{2}$ and $\mathrm{M}_{3}$ host specificity type respectively (Table 5 ). Concentrated cell suspensions of the staphylococcal strains were infected with labelled lysates of the two phages. Under the experimental conditions used, adsorption as measured by the decrease in p.f.u. $/ \mathrm{ml}$ was almost complete, i.e. 95 to $98 \%$. Phage DNA degradation, measured by the appearance of cold-acid-soluble radioactive label in samples of the total adsorption mixture, does not occur upon infection of a restrictionless or compatible host and the level of cold-acidsoluble label remained constant during incubation. In contrast, infection of a restricting host was followed by a rapid and sometimes extensive breakdown of phage DNA. The restricting hosts showed this increase in radioactive label consistently in each experiment. The results strongly suggest that in these staphylococci inappropriately modified phage DNA is recognized as foreign and in consequence is degraded. 


\section{DISCUSSION}

The dependance of the host range of a phage on its propagating strain (Tables $I, 2,3$ ), and the rapid degradation of phage DNA upon infection of an insusceptible host (Table 5), can be accounted for by assuming that the phages undergo host-controlled modification and restriction, the characteristics of which have recently been reviewed (Arber \& Linn, 1969). The results presented exclude the possibilities of mutant selection or the selection of a contaminating phage particle (Table 2), because the host specificity of a phage is reversible. The efficiency of plating of phage $7 \mathrm{I} .240$ and of phage $7 \mathrm{I} .240 .382 .240$ on different hosts are the same (Table 2).

Strain 407 shows no alteration in the capacity to restrict phage after lysogenization with different temperate phages (Table 4). Phages propagated on several lysogenic derivatives of strain 407 kept the modification type M3 (J. Verhoef, unpublished data). Thus the lysogenizing phage does not appear to carry modification and restriction loci. Table 5 suggests that restricting cells recognize and degrade incompatible modified phage DNA.

The classification of strains and phages according to their phage susceptibility and host range respectively (Table I) represents the occurrence of three different host specificity types among the Staphylococcus subgroup II strains. The phage patterns of these Staphylococcus epidermidis strains appear to be mainly determined by the host specificity type carried by the strains. Immunity due to lysogeny is probably superimposed on this, and accounts for the variation observed within one host specificity system (see Tables I, 4).

The phenomenon of host-controlled modification and restriction has been encountered in many bacterial species, including Staphylococcus aureus (Ralston \& Krueger, 1952; 1954; Rountree, I956; Asheshov \& Jevons, I963; Ralston \& Baer, I964a, b, c).

The phage patterns among these Staphylococcus subgroup I strains are generally considered to be determined by lysogeny which occurs almost universally among them. However, the observations regarding the relationship between host range of typing phages and their propagating strains (Ralston \& Baer, $1964 a, b, c$ ) and the observations of Asheshov \& Jevons (I963) suggest that host-controlled restriction and modification is also involved in coagulase-positive staphylococci.

Among the coagulase-negative subgroup II strains, two groups of strains are of interest: the relatively frequently occurring strains susceptible to all phages and the non-typable strains. The former probably are restrictionless. Whether the latter strains are insensitive due to lysogeny or to restriction exerted by another host specificity system or for other reasons remains to be elucidated.

The authors wish to thank Professor Dr K. C. Winkler, Dr W. P. M. Hoekstra, Dr H. J. J. Nijkamp (Laboratory of Microbiology, Utrecht) Dr P. Ch-van der Vliet (Laboratory of Physiological Chemistry, Utrecht) and Dr B. A. M. van der Zeyst (Laboratory of Physical Chemistry, Utrecht) for their contribution to and constant interest in the work. 


\section{REFERENCES}

Arber, W. \& Linn, S. E. (1969). DNA modification and restriction. Annual Review of Microbiology $\mathbf{3}^{8}$, $467-500$.

Asheshov, E. A. \& Jevons, M. P. (1963). The effect of heat on the ability of a host strain to support the growth of a staphylococcal phage. Journal of General Microbiology 3r, 97-107.

BAIRD-PARKer, A. C. (1963). A classification of micrococci and staphylococci based on physiological and biochemical tests. Journal of General Microbiology 30, 309-427.

Baird-Parker, A. C. (1965). Staphylococci and their classification. Annals of the New York Academy of Science 128, 4-19.

Blair, J. E. \& Williams, R. E. O. (I96I). Phage typing of staphylococci. Bulletin of the World Health Organization 24, 77I-784.

VAn Boven, C. P. A., Verhoef, J. \& Winkler, K. C. (1969). Bacteriophage typing of coagulase-negative staphylococci. Antonie van Leeuwenhoek 35, 232.

RALSTON, D. J. \& BAER, B. S. (I 964a). A new property of phage group II Staphylococcus aureus strains: Host restriction of phage $\mathrm{K}_{14}$. Journal of General Microbiology $36,1-16$.

Ralston, D. J. \& BAER, B. S. (1964b). Propagation of staphylococcal phages on a common host. Staphylococcus aureus $\mathrm{K}_{1}$, and host-controlled changes in their lytic range. Journal of General Microbiology $\mathbf{3}^{6}$, 17-24.

Ralston, D. J. \& BAER, B.S. (1964c). Host-controlled changes of staphylococcal phage $3 \mathrm{C}$ affecting its broad group typing pattern. Journal of General Microbiology 36, 25-36.

Ralston, D. J. \& Krueger, A. P. (I952). Phage multiplication on two hosts. Isolation and activity of variants of staphylococcus phage $\mathrm{P}_{1}$. Proceedings of the Society for Experimental Biology and Medicine 8o, $217-220$.

Ralston, D. J. \& Krueger, A. P. (I954). The isolation of staphylococcal phage variant susceptible to an unusual host control. Journal of General Physiology 37, 685-716.

RountreE, P. M. (1956). Variation in a related series of staphylococcal bacteriophages. Journal of General Microbiology 15, 266-279.

Verhoef, J., Van Boven, C. P. A. \& Holtrigter, B. (I971). Restriction and modification of phages in coagulase-negative staphylococci. Antonie van Leeuwenhoek 37, 256-257.

Verhoef, J., VAN Boven, C. P. A. \& WinkLer, K. C. (197I a). Lysogeny in coagulase-negative staphylococci. Journal of Medical Microbiology 4, 405-412.

Verhoef, J., van Boven, C. P. A. \& Winkler, K. C. ( I 97 I $b$ ). Characters of phages from coagulase-negative staphylococci. Journal of Medical Microbiology 4, 4I 3-424.

Verhoef, J., van Boven, C. P. A. \& Winkler, K. C. (1972). Phage typing of coagulase-negative staphylococci. Journal of Medical Microbiology (in the press). 